\title{
Comportamento fenológico no evento pós-queima e biologia reprodutiva de Spiranthera odoratissima A. St.-Hil. (Rutaceae)
}

\author{
Cristiane Soares Pereira da Silva* \\ Mirley Luciene dos Santos \\ Universidade Estadual de Goiás, Unidade Universitária de Ciências Exatas e Tecnológicas, Campus BR 153, \\ Laboratório de Biodiversidade, CEP 75001-970, Anápolis - GO, Brasil \\ *Autor para correspondência \\ criskrol@terra.com.br
}

Submetido em 25/06/2007

Aceito para publicação em 12/11/2007

\section{Resumo}

O comportamento fenológico das espécies de cerrado influenciadas pela ação de queimadas é pouco conhecido. O estudo da fenologia e biologia reprodutiva de Spiranthera odoratissima A. St.-Hil. foi realizado em uma área antropizada de cerrado sensu stricto submetida ao fogo no município de Goiânia, Goiás. Observações fenológicas evidenciaram que os indivíduos floresceram sincronicamente três meses após a queima. Os ritmos fenológicos estiveram associados aos efeitos da sazonalidade pluviométrica, padrão característico das espécies subarbustivas de cerrado. As flores são brancas, de odor adocicado e estão reunidas em inflorescências paniculadas. A antese é crepuscular e inicia-se por volta das $16 \mathrm{~h}$. Os recursos oferecidos aos visitantes são pólen e néctar. A espécie produz $32,8 \mu 1( \pm 3,4)$ de néctar com concentração média de $16,4 \%( \pm 0,43)$ em equivalentes de sacarose. O sistema de polinização (falenofilia) foi proposto com base na análise das características florais. Os visitantes observados foram abelhas (Apis mellifera Linnaeus), moscas, vespas, formigas e besouros, porém, devido ao comportamento na inflorescência, foram considerados apenas pilhadores de recursos. Foi constatado que Trigona spinipes Fabr. pode atuar como polinizador secundário durante a pilhagem de pólen. Os resultados das polinizações manuais e o índice de incompatibilidade (ISI) indicam que a espécie é xenógama e auto-compatível.

Unitermos: fogo, sazonalidade, falenofilia, xenogamia, manacá, cerrado

\section{Abstract}

Post-fire phenological behavior and breeding biology of the Spiranthera odoratissima A. St.-Hil. (Rutaceae). The phenological behavior of species in response to cerrado stricken by fire is little known. A phenological and reproductive biological study of Spiranthera odoratissima was carried out in an anthropized area of cerrado sensu stricto affected by fire in Goiânia County, Goiás, Brazil. Phenolocial observations indicated that the individuals bloomed in synchrony three months after the fire. The phenological rhythms were associated with the seasonal pluviometric effects, a characteristic pattern of shrublet species of the cerrado. The flowers are white with a sweet odor and are grouped in panicle inflorescences. The blossoming occurs during dusk and begins at around 16h. It offers pollen and nectar to its visitors. The species produces $32.8 \mu \mathrm{l}( \pm 3.4)$ of nectar with an average concentration of $16.4 \%( \pm 0.43)$ in equivalents of sucrose. The pollination system (phalenophily) was proposed based on an analysis of the flower's characteristics. Observed visitors were bees (Apis 
mellifera Linnaeus), flies, wasps, ants and beetles, but due to the inflorescence behavior, they were considered to be merely resource thieves. It was observed that Trigona spinipes Fabr. can act as a secondary pollinator during the pilling of pollen. The results of manual pollination and the incompatibility index (ISI) indicate that the species is xenogamous and self-compatible.

Key words: fire, seasonality, phalenophily, xenogamy, manacá, cerrado

\section{Introdução}

Spiranthera odoratissima A. St.-Hil. (Rutaceae) é uma espécie de cerrado ameaçada de extinção, que vem sendo submetida a um alto grau de impactos, como extrativismo das raízes para fins medicinais e perda constante de hábitat ocasionada pela urbanização e ampliação da fronteira agrícola (Mendonça e Lins, 2000). Os conhecimentos biológicos ao seu respeito são escassos, principalmente em relação aos aspectos da biologia floral e reprodutiva e ao comportamento fenológico da espécie após o fogo, evento que é muito comum em áreas de cerrado durante os períodos de baixos índices pluviométricos.

A sazonalidade pluviométrica influencia diretamente os padrões fenológicos das espécies de cerrado, na qual exerce um importante papel para a dinâmica e a estruturação das savanas tropicais (Batalha e Mantovani, 2000; Munhoz e Felfili, 2005). Entre as espécies arbóreas e decíduas, ocorre a perda completa das folhas durante a seca (Lenza e Klink, 2006) e indícios mostram que a restrição de água neste período não impede a renovação da folhagem e a ocorrência da floração (Oliveira e Gibbs, 2000; Lenza e Klink, 2006). Este comportamento é possível devido à presença de sistemas radiculares bem desenvolvidos que alcançam camadas profundas do solo, onde a água está disponível (Oliveira et al., 2005). Em contrapartida, os eventos fenológicos das espécies herbáceas e subarbustivas são sensivelmente afetados pela escassez pluviométrica, pois possuem raízes superficiais (Munhoz e Felfili, 2005). De um modo geral, estas espécies apresentam uma acentuada diminuição da floração durante a estação seca, especialmente nos meses de junho a agosto, havendo a concentração de espécies florescendo na estação chuvosa (Batalha et al., 1997; Batalha e Mantovani, 2000).

A ocorrência de queimadas, que também varia sazonalmente, pode ocasionar comportamentos fenológicos divergentes aos padrões comumente descritos para as espécies lenhosas e herbáceo-subarbustivas, principalmente em relação aos eventos reprodutivos (Bulhão e Figueiredo, 2002).

Em ambientes de cerrado, a composição florística é influenciada diretamente por uma combinação de condições edáficas, sazonalidade e fogo, que juntos contribuíram para a evolução e a seleção de sua flora (Eiten, 1994). Estima-se que a ocorrência de queimadas no cerrado é mais antiga que 32 mil anos; deste modo, o longo período de ocorrência de incêndios permitiu que muitas espécies tornassem tolerantes ou até mesmo dependentes do fogo para a reprodução (Coutinho, 2002). Raison (1977) destaca quatro efeitos do fogo nas comunidades vegetais: 1) acelera a ciclagem de nutrientes, promovendo um aumento na quantidade e disponibilidade de cálcio, potássio e magnésio pela deposição de cinzas; 2) remove a vegetação excedente do solo, permitindo que este receba mais intensamente os raios solares, garantindo o estabelecimento de espécies menores e mais delgadas que têm dificuldades de crescer sobre a matéria seca acumulada; 3) exerce o efeito de poda, promovendo uma imensa capacidade regenerativa; e 4) possível influência na quebra de dormência de sementes que apresentam testa espessa e rígida.

O desenvolvimento de pesquisas sobre os eventos fenológicos e os sistemas de polinização e reprodução das plantas é fundamental para a melhor compreensão da biodiversidade do Cerrado. É através destes estudos que se torna possível estabelecer ferramentas úteis para a conservação e o manejo das comunidades vegetais, visto que o bioma Cerrado engloba uma das mais ricas e ameaçadas diversidades taxonômicas do planeta (Myers et al., 2000).

Considerando que as espécies dos ambientes de cerrado possuem diferentes estratégias fenológicas que lhes permitem superar as diferentes condições ambientais às quais estão sujeitas, como fogo e estresse hídrico sazonal, este estudo teve como objetivos: 1) descrever o comportamento fenológico vegetativo e reprodutivo 
de $S$. odoratissima após a passagem do fogo; 2) verificar se os eventos fenológicos observados se relacionam com a sazonalidade pluviométrica, conforme proposto na literatura para as espécies subarbustivas de ambientes savânicos (Batalha e Mantovani, 2000; Spina et al., 2001; Munhoz e Felfili, 2005); e 3) contribuir para a ampliação do conhecimento biológico da espécie, tais como morfologia e biologia floral, síndrome de polinização e sistema reprodutivo.

\section{Material e Métodos}

\section{Espécie estudada}

Spiranthera odoratissima A. St.-Hil. (Rutaceae) é uma espécie medicinal que ocorre em formações savânicas e campestres do bioma Cerrado. Possui hábito subarbustivo, com até $1,5 \mathrm{~m}$ de altura; as raízes são amareladas e aromáticas; as folhas são alternas, compostas, trifolioladas, cartáceas, e apresentam glândulas translúcidas; as flores são brancas e perfumadas e estão reunidas em inflorescências paniculadas; os frutos são cápsulas esquizocárpicas, incompletas, deiscentes e septicidas.

A espécie está distribuída nos Estados de Goiás, Minas Gerais, Bahia, Mato Grosso e no Distrito Federal (Almeida et al., 1998). Encontra-se na lista de espécies ameaçadas da flora de Minas Gerais, enquadrando-se na categoria vulnerável (Mendonça e Lins, 2000), ameaça que é atribuída, principalmente, à sobre-exploração de suas raízes para fins medicinais. Popularmente, é conhecida como manacá nos Estados de Mato Grosso e Goiás (Freitas et al., 2002; Tresvenzol et al., 2006), cheirosa no Estado de Minas Gerais (Mendonça e Lins, 2000), e acabadeira ou sarrinha no Estado da Bahia (Freitas et al., 2002).

Investigações etnobotânicas sobre o manacá revelam que a comercialização de suas raízes é realizada com freqüência nos mercados e feiras livres de Goiânia, GO, sendo vendidas in natura ou associadas com outras plantas na composição de garrafadas para o tratamento de reumatismo (Tresvenzol et al., 2006). Outras referências etnofarmacológicas mostram que o chá das raízes é utilizado para dores de estômago, dores de cabeça, dores musculares, disfunções hepáticas e para estimular o apetite (Vieira e Martins, 2000) e o extrato etanólico das raízes apresenta compostos com atividade analgésica e antiinflamatória (Matos et al., 2004).

\section{Local de estudo}

A coleta de dados ocorreu no município de Goiânia, Goiás, em ambiente de cerrado sensu stricto profundamente alterado pela expansão de loteamentos residenciais na área e proximidade com a região urbana. Os eventos de queima são realizados intencionalmente pelos moradores do local no final da estação seca, como forma de eliminar o excesso de matéria vegetal seca proveniente do estrato herbáceo. A área de estudo está delimitada pelas coordenadas geográficas 16038'19"

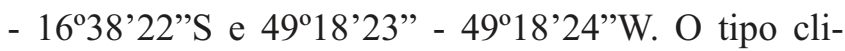
mático predominante é o Aw, caracterizado por duas estações bem definidas marcadas por invernos secos, de abril a outubro, e verões chuvosos, de novembro a março. A temperatura média anual é de $23,2^{\circ} \mathrm{C}$, com mínima de $17,7^{\circ} \mathrm{C}$ e máxima de $29,8^{\circ} \mathrm{C}$. A precipitação média anual gira em torno de $1.575,9 \mathrm{~mm}$, onde mais de $70 \%$ do total de chuvas acumuladas durante o ano se precipitam na estação chuvosa (Brasil, 1992).

\section{Coleta de dados}

O trabalho de campo foi realizado entre julho de 2003 e agosto de 2004, somando um ano de observações. O fogo, que definiu o comportamento fenológico da espécie após o evento de queima, ocorreu na primeira semana do mês de julho/2003. Foram selecionados, de forma aleatória, dez indivíduos para a coleta de dados fenológicos e cinco indivíduos para os estudos de biologia reprodutiva. O número amostral reduzido é justificado pelo fato da espécie ocorrer em populações pequenas e isoladas (Mendonça e Lins, 2000).

Quando se trabalha com indivíduos de pequeno porte, onde se tem acesso visual livre das copas é recomendada, normalmente, uma amostragem absoluta e posterior conversão em porcentagem. No entanto, foram adotadas quantificações subjetivas das fenofases brotação foliar, floração (botões florais e flores abertas) e frutificação (frutos iniciados, verdes e maduros), 
que foram acompanhadas quinzenalmente e registradas pelo método de Fournier (1974) com intervalos de classes de 0 a 4, sendo: 0 - ausência do evento; 1 - 1 a 25\% do evento em copa; 2 - 26 a $50 \%$ do evento em copa; $3-51$ a $75 \%$ do evento em copa; e $4-76$ a $100 \%$ do evento em copa.

A morfologia floral foi estudada a partir de material fresco e fixado em FAA 50\%. Cinco botões florais de indivíduos distintos e em pré-antese foram selecionados aleatoriamente, marcados com linhas coloridas e acompanhados através de observações não sistematizadas a partir da abertura para o registro de informações como: início da antese, receptividade do estigma, duração da flor e processo de senescência dos componentes florais. $\mathrm{O}$ início da antese foi caracterizado por uma pequena abertura no ápice da flor. Adicionalmente, foi registrado o número total de botões florais e flores produzidos por três indivíduos influenciados e não influenciados pelo fogo, na mesma área e período de observações.

Para o estudo da biologia reprodutiva, foram avaliadas a viabilidade dos grãos de pólen, e o volume e a concentração de açúcares no néctar. A disponibilidade e viabilidade dos grãos de pólen foram determinadas, respectivamente, através de observações de campo e do uso de corante carmim acético e análises microscópicas em 25 flores (Dafni, 1992). Para a avaliação do volume de néctar, 12 flores selecionadas aleatoriamente $\mathrm{e}$ em processo de abertura foram previamente isoladas em sacos de organza e marcadas com linhas coloridas. Na manhã seguinte à antese, que é crepuscular, a quantidade de néctar foi tomada entre às $8 \mathrm{~h} 00$ e 9h00, sendo efetuada com micropipetas de $20 \mu 1$ (BlaubrandIntraMark $\left.^{\circledR}\right)$ introduzidas na base da corola. Foi utilizado um refratômetro de mão (Atago ${ }^{\circledR}$ ) para estimar a concentração do néctar coletado em "equivalentes de sacarose".

Foram feitos testes de polinizações controladas para o estudo do sistema reprodutivo. Os pedicelos das flores e inflorescências foram marcados com fios de cores distintas contendo a data do tratamento realizado. Botões florais em pré-antese foram selecionados de forma aleatória e isolados previamente em sacos de organza, sendo as flores submetidas a quatro tratamen- tos adaptados de Bawa (1974): 1) autopolinização espontânea $(\mathrm{n}=139)$ - seis inflorescências de indivíduos distintos contendo botões florais em pré-antese foram apenas ensacadas para a verificação da formação de frutos; 2) autopolinização manual $(n=42)$ - grãos de pólen produzidos pela flor foram depositados sobre o seu próprio estigma (geitonogamia), sendo a inflorescência novamente ensacada; 3) polinização cruzada manual $(\mathrm{n}=53)$ - grãos de pólen provenientes de flores de indivíduos mais distantes foram depositados no estigma da flor receptora, sendo a inflorescência novamente ensacada; 4) apomixia $(n=42)$ - botões florais em pré-antese tiveram todas as anteras extraídas, sendo, posteriormente ensacados. Nos dois últimos tratamentos (cruzado e apomixia), foram retiradas todas as anteras dos botões florais em pré-antese a fim de evitar a contaminação com o próprio pólen. Para a avaliação da eficiência de polinização natural, seis inflorescências de indivíduos distintos foram marcadas e mantidas expostas, sendo verificado o número de frutos formados pelo tratamento controle $(n=127)$. Os sacos de organza foram retirados uma semana após os tratamentos visando minimizar possíveis influências nos resultados das polinizações.

O índice de incompatibilidade (ISI) foi estimado pela razão entre a porcentagem de frutos obtidos pela autopolinização manual e frutos obtidos pela polinização cruzada (Bullock, 1985). Foi calculada, também, a eficácia reprodutiva, que é a razão entre o percentual de frutos formados pela polinização natural (controle) e pela polinização cruzada manual (Zapata e Arroyo, 1978).

Pistilos tratados com autopolinizações manuais e polinizações cruzadas foram coletados e fixados em FAA $50 \%$ em intervalos de 12, 24, 36 e 48 horas. Estes foram encaminhados para o laboratório da Universidade Federal de Uberlândia (UFU-MG) aonde, utilizando-se a técnica de microscopia de fluorescência (Martin, 1959), observou-se o crescimento dos tubos polínicos. Observações adicionais e não sistematizadas da germinação das sementes resultantes das autopolinizações manuais foram efetuadas a fim de avaliar a possível existência de um sistema de auto-incompatibilidade de ação tardia. 
Observações não sistematizadas dos visitantes florais foram realizadas durante todo o trabalho de campo, concomitantemente à coleta de dados fenológicos e aos demais experimentos de biologia floral e reprodutiva, no horário compreendido entre $7 \mathrm{~h} 00$ e $18 \mathrm{~h} 00$. Observações noturnas não foram realizadas. O sistema de polinização foi estimado pela análise das características florais propostas por Faegri e van der Pijl (1979). Os visitantes florais observados foram considerados pilhadores de recursos com base no comportamento ao chegar e ao deixar a flor.

O material botânico testemunho se encontra depositado no Herbário da Universidade Estadual de Goiás sob os registros 1209 a 1211.

\section{Resultados}

\section{Comportamento fenológico}

Spiranthera odoratissima iniciou a emissão de novos ramos e brotos foliares em cerca de 30 dias após a passagem do fogo (Figura 1). No mês de setembro, cerca de 60 dias após o fogo, a nova parte aérea estava completamente formada e iniciou o processo de floração. $\mathrm{O}$ auge da floração ocorreu na primeira quinzena de outubro, três meses após a queima.
Foi observada uma alternância entre rebrota e floração nos meses de setembro e outubro (Figura 1), comportamento que pode ser explicado pela alocação dos recursos para a produção de flores. Nesse caso, sugere-se que a menor disponibilidade hídrica decorrente dos baixos índices pluviométricos durante a estação seca possa reduzir ou mesmo estagnar a rebrota foliar a fim de garantir recursos para uma floração intensa.

Apesar da grande produção de flores e da sincronização da floração entre os indivíduos após a queimada, a formação de frutos foi um evento discreto. Os frutos verdes só foram observados em fevereiro, quatro meses após o auge da floração. A dispersão dos diásporos ocorreu no final da estação chuvosa e início da estação seca, apresentando um comportamento de frutificação claramente estacional.

\section{Morfologia e visitantes florais}

As flores de S. odoratissima são brancas, hermafroditas, actinomorfas, apresentam corola dialipétala e estão reunidas em inflorescências paniculadas e terminais. Durante o pico de floração (outubro/2003), foi constatada uma média de $23 \pm 8$ inflorescências por indivíduo $(\mathrm{n}=3)$ e uma média de $21 \pm 7,6$ flores por inflorescência $(\mathrm{n}=70)$. Observações adicionais em três indivíduos não queimados revelaram que a produção

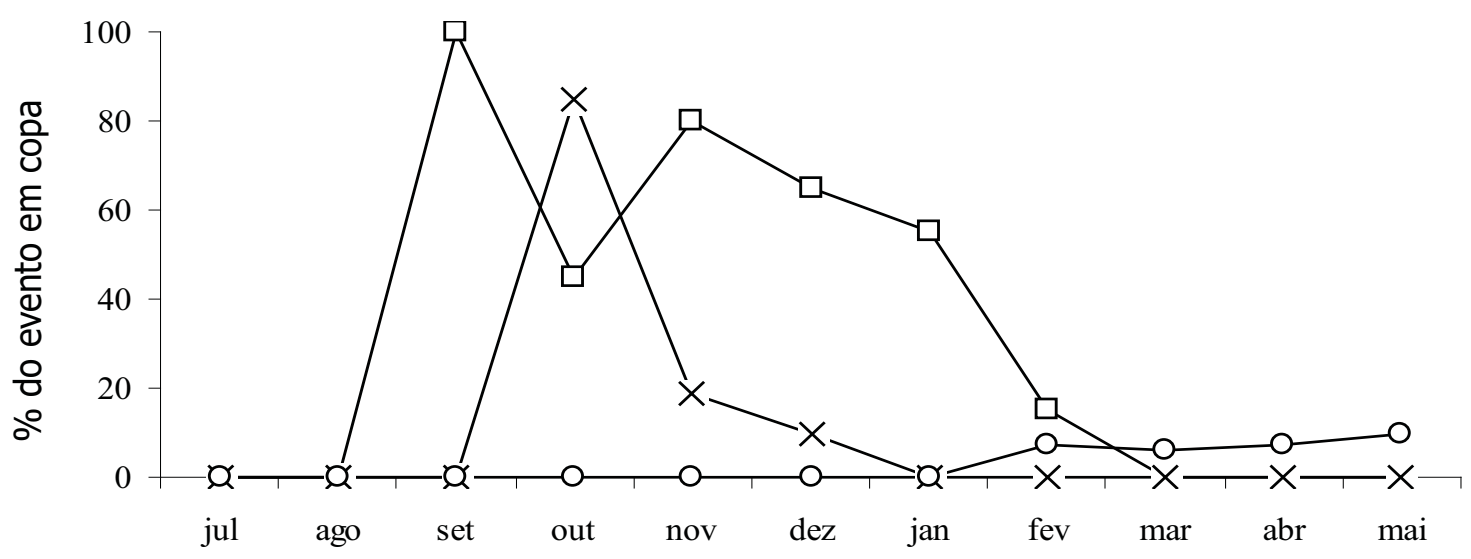

FIGURA 1: Intensidades fenológicas de dez indivíduos de Spiranthera odoratissima A. St.-Hil. influenciados pelo fogo no município de Goiânia, GO, Brasil. Brotação foliar ( $\square$ ); floração (x) e frutificação para frutos verdes e maduros (o). 
de flores foi discreta, sendo computadas uma média de $5 \pm 2$ inflorescências por indivíduo $(\mathrm{n}=3)$ e uma média de $14 \pm 5,5$ flores por inflorescência $(n=14)$, na mesma área e período de observações.

As pétalas apresentam 4,32 $\pm 0,07 \mathrm{~cm}$ de comprimento. $\mathrm{O}$ androceu é formado por estames hipóginos, com filetes longos, filiformes e alvos, e anteras bitecas de deiscência longitudinal e cor amarelada. Os elementos florais que compõem o androceu, o cálice e a coro- la ocorrem, predominantemente, em número de cinco, podendo ocorrer algumas variações com número de seis elementos. O gineceu é constituído por um estigma penta ou hexacaptado, estilete filiforme e ovário súpero penta ou hexalobado com um óvulo por lóculo (Figura 2). O fruto é uma cápsula esquizocárpica, com 1 a 6 mericarpos deiscentes. A semente é oval, amarronzada, arilada, e apresenta 0,7-1 cm de comprimento.
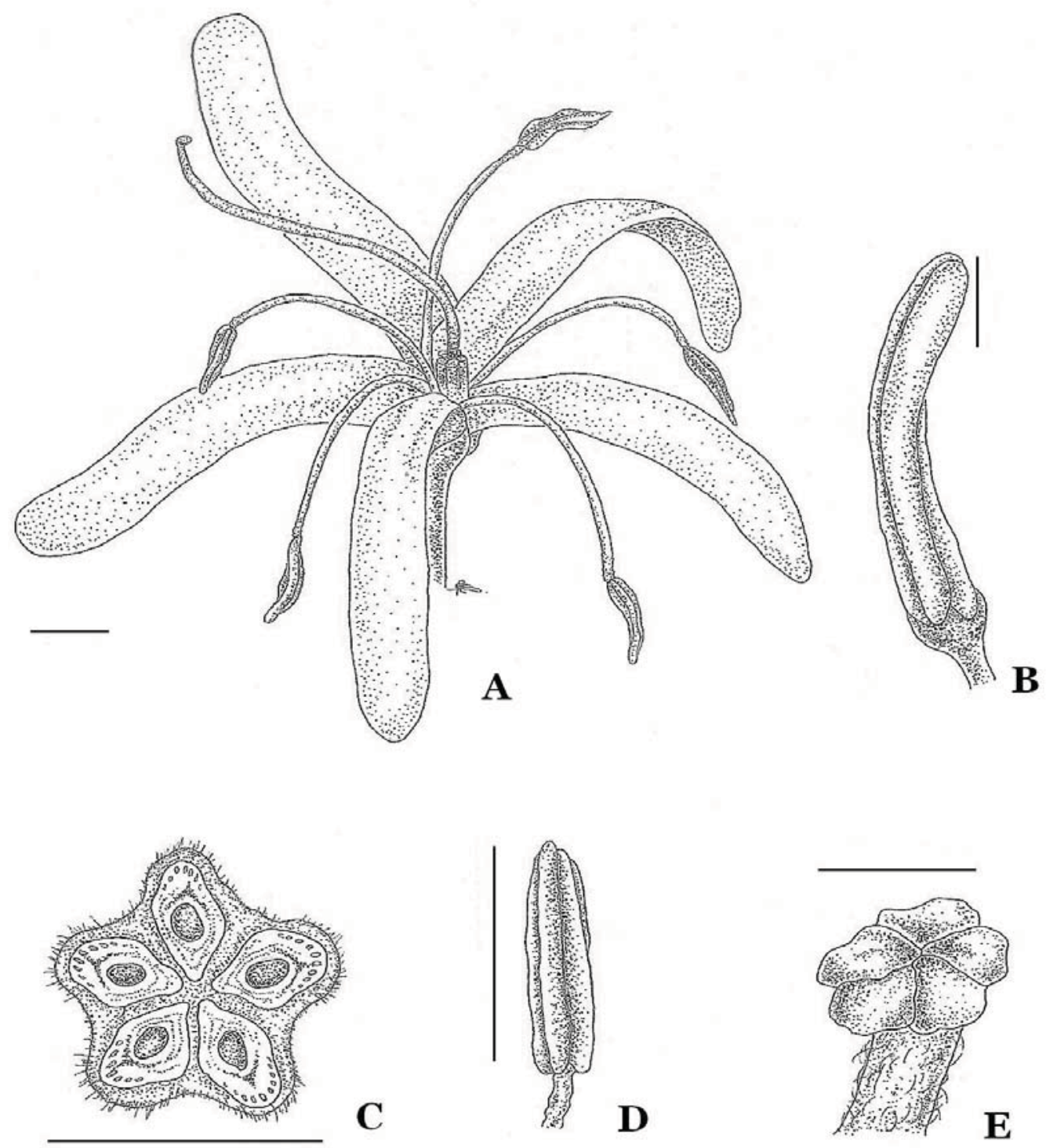

D

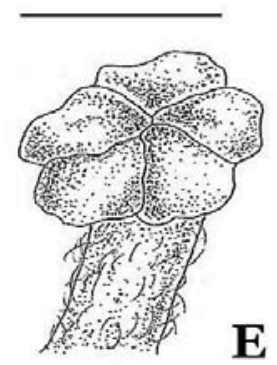

FIGURA 2: Morfologia floral de Spiranthera odoratissima A. St.-Hil. (Rutaceae). A. Aspecto geral da flor. B. Botão floral na pré-antese. C. Corte transversal do ovário pentalocular. D. Detalhe da antera basifixa. E. Superfície estigmática. Escala gráfica em A, B e D corresponde a $1 \mathrm{~cm}$. Em C e E correspondem, respectivamente, $3 \mathrm{~mm}$ e $1 \mathrm{~mm}$. 
A antese ocorre no final da tarde, por volta das $16 \mathrm{~h} 00$, prolongando-se até às $18 \mathrm{~h} 00$. As flores produzem odor intenso, suave e doce, desde a abertura. As primeiras flores a se abrirem são as da base, havendo grande variação na quantidade que se abre por dia. No início da antese, o estigma parece estar receptivo, porém os grãos de pólen só são liberados no período crepuscular, horário em que, provavelmente, a flor é polinizada. No momento da antese, a viabilidade do pólen foi de $97,4 \%( \pm 0,69 ; n=25)$.

Os recursos oferecidos pelas flores aos visitantes são pólen e néctar. $\mathrm{O}$ néctar é produzido por um disco nectarífero de cor branco-amarelada, na base do ovário, sendo adocicado e pouco viscoso. A média da concentração de açucares em equivalentes de sacarose no néctar de $S$. odoratissima foi de $16,4 \%( \pm 0,43 ; \mathrm{n}=$ 12). $\mathrm{O}$ volume médio de néctar por flor foi de $32,8 \mu 1$ $( \pm 3,4 ; \mathrm{n}=12)$.

Os elementos da corola e do androceu apresentaram curta duração e mostram sinais de senescência 24 horas após a antese. O processo de senescência da corola caracterizou-se pela desidratação, amarelecimento e queda das pétalas. O processo de senescência do androceu caracterizou-se pelo ressecamento das anteras e dos filetes e posterior queda dos mesmos. Mesmo com a inexistência de atrativos florais, como pétalas, pólen, néctar e odor, o estigma permaneceu receptivo por até 48 horas após a antese, quando se evidenciou o murchamento e escurecimento da superfície estigmática seguida da queda do estilete.

Durante o período da floração, as flores foram intensamente visitadas por diversos insetos. As visitas iniciavam-se por volta das $7 \mathrm{~h} 00$ e se intensificavam entre $8 \mathrm{~h} 00$ e $10 \mathrm{~h} 00$ da manhã. Após este período, a oferta de recursos tornava-se escassa em decorrência da alta visitação de insetos pilhadores. No entardecer, entre $16 \mathrm{~h} 00$ e $18 \mathrm{~h} 00$, foram observadas algumas abelhas da espécie Apis mellifera Linnaeus, que pilhavam o néctar que começava a se acumular na flor.

Trigona spinipes Fabr. foi o pilhador de pólen mais freqüente, conseguindo carregar uma grande quantidade de grãos de pólen em suas corbículas. Durante as visitas, essas abelhas encostavam o corpo piloso impreg- nado de grãos de pólen no estigma das flores, podendo efetuar a polinização. Devido à sua longa permanência em uma mesma planta e à baixa movimentação entre os indivíduos de $S$. odoratissima, $T$. spinipes pode promover a geitonogamia.

Apis mellifera foi o pilhador de néctar mais abundante. Em menor freqüência, foram observadas moscas (Syrphidae), vespas (Eumenes sp.), formigas (Gnamptogenys sp.) e coleópteros (Lagria vilosa Fabr.), que visitaram as flores à procura de néctar ou pólen, sem, no entanto, entrarem em contato com os órgãos sexuais da flor.

\section{Sistema de reprodução}

Spiranthera odoratissima forma frutos, preferencialmente, através de polinizações cruzadas (Tabela 1). Não houve formação de frutos por autopolinização espontânea, indicando que a espécie necessita da ação de agentes polinizadores para a transferência de grãos de pólen das anteras para a superfície estigmática. $\mathrm{O}$ sucesso de frutificação das flores oriundas de autopolinização manual foi de $16,67 \%$. Obteve-se o índice de auto-incompatibilidade (ISI) de 0,55 , indicando que a espécie é auto-compatível.

Os frutos obtidos em condições naturais (controle) foi menor que a taxa de polinização cruzada manual e a autopolinização manual (Tabela 1), sugerindo uma provável deficiência dos visitantes florais como polinizadores. A eficácia reprodutiva foi de 0,39 (sensu Zapata e Arroyo, 1978).

TABELA 1: Resultados dos experimentos de polinizações controladas em flores de Spiranthera odoratissima A. St.-Hil. (Rutaceae) e índice de incompatibilidade (ISI*) em área antrópica de cerrado sensu stricto no município de Goiânia, GO, Brasil.

\begin{tabular}{l|c|c}
\multicolumn{1}{c|}{ Tratamentos } & $\begin{array}{c}\text { Flores / } \\
\text { Frutos }\end{array}$ & $\begin{array}{c}\text { Sucesso } \\
\text { reprodutivo } \\
\text { (\%) }\end{array}$ \\
\hline Autopolinização espontânea & $139 / 00$ & 0,00 \\
\hline Autopolinização manual & $42 / 07$ & 16,67 \\
\hline Polinização cruzada & $53 / 16$ & 30,18 \\
\hline Apomixia & $42 / 00$ & 0,00 \\
\hline Controle & $127 / 15$ & 11,81 \\
\hline ISI $^{*}=0,55$ & &
\end{tabular}


A observação dos tubos polínicos em microscopia de fluorescência revelou que nenhuma diferença em relação à velocidade de germinação e crescimento foi constatada nas regiões do estigma e do estilete de pistilos tratados com autopolinizações manuais e polinizações cruzadas. Após doze horas, foram observados tubos polínicos na região do ovário em ambos os tratamentos. Não foi constatada nenhuma reação de auto-incompatibilidade nos pistilos autofecundados. $\mathrm{O}$ teste de germinação das sete sementes provenientes das autopolinizações manuais revelou que $71,42 \%$ delas germinaram, evidenciando que $S$. odoratissima não apresenta sistema de incompatibilidade de ação tardia, pois, nesse caso, as sementes não desenvolvem embriões viáveis e, portanto, não germinam.

\section{Discussão}

\section{Comportamento fenológico}

A fenologia de uma espécie depende de suas características adaptativas e das condições ambientais às quais está sujeita. Os eventos de queima, por exemplo, são comuns no cerrado e suas comunidades vegetais apresentam comportamentos fenológicos diferenciados após o fogo (Sarmiento, 1992; Bulhão e Figueiredo, 2002; Munhoz e Felfili, 2005). Entre as espécies herbáceas e subarbustivas, o fogo promove a floração sincrônica (Sarmiento, 1992; Munhoz e Felfili, 2005) e pode favorecer a reprodução sexuada entre os indivíduos da população (Miranda e Klink, 1996). Já na comunidade arbórea, a ocorrência freqüente de queimadas aumenta a mortalidade de indivíduos e afeta negativamente a reprodução sexuada, ocasionando uma diminuição significativa no número de flores e na produção de frutos e sementes (Bulhão e Figueiredo, 2002).

Os dados fenológicos registrados após a passagem do fogo evidenciaram que Spiranthera odoratissima se encontra adaptada a uma condição ambiental que inclui a presença de queimadas. Essa adaptação é possível devido à proteção de seu sistema radicular pela camada de terra, que se torna um importante isolante térmico, impedindo a elevação da temperatura do solo e o conseqüente comprometimento das raízes (Coutinho, 1978 e 2002). Normalmente, as espécies que pertencem ao estrato herbáceo-subarbustivo começam a rebrotar após o fogo, pois o sistema radicular funciona como órgãos de resistência (Coutinho, 1977). Em algumas espécies subarbustivas, como o observado em Anemopaegma arvense (Vell.) Stellfeld \& J. F. Souza (catuaba), Jacaranda decurrens Cham. (carobinha) (Coutinho, 1977) e entre $S$. odoratissima, a rebrota e a restauração da parte aérea é seguida imediatamente pela produção de flores, onde o fogo atua como agente sincronizador da floração.

No bioma Cerrado, as alterações periódicas de disponibilidade de água definem a existência de dois períodos climáticos bem definidos, marcados por invernos secos, de abril a setembro, e verões chuvosos, de outubro a março (Eiten, 1994). Assim, a ocorrência do fogo na estação seca permite que a sazonalidade também influencie nos ritmos fenológicos; isso porque as espécies de hábito subarbustivo, como o manacá, são sensivelmente afetadas pela escassez pluviométrica e florescem, preferencialmente, nos períodos em que há água disponível no solo (Batalha et al., 1997; Batalha e Mantovani, 2000; Munhoz e Felfili, 2005). Estas evidências corroboram os dados observados, visto que a brotação foliar e a floração do manacá foram rapidamente estimuladas para coincidir com o início da estação chuvosa. No entanto, o período compreendido entre os frutos iniciados e os frutos maduros foi prolongado e se estendeu por mais de três meses a partir dos experimentos de polinizações controladas. Sugere-se que este comportamento seja para que a dispersão das sementes coincida com a chegada da estação seca, uma vez que espécies autocóricas dependem da baixa umidade do ar para o dessecamento do pericarpo e a liberação dos diásporos. Há evidencias de que o comportamento de floração e frutificação da espécie seja claramente estacional, mesmo quando submetida à influência do fogo. Porém, observações fenológicas prolongadas e uma análise de correlação seriam mais indicadas para se estabelecer a possível conexão entre os dados climáticos e os eventos de queima.

De forma complementar, estudos conduzidos em área de cerrado na Floresta Nacional de Silvânia, Goiás, que há 20 anos não havia sido submetida ao fogo, 
constataram que a floração de $S$. odoratissima também foi marcadamente sazonal e a brotação foliar e a floração estiveram relacionadas com a estação chuvosa, comportamento que está em concordância com outras espécies subarbustivas já investigadas (Batalha et al., 1997; Batalha e Mantovani, 2000; Spina et al., 2001). $\mathrm{Na}$ área isenta de queimadas, a floração do manacá foi um evento discreto durante um ano de observações, constituindo um reflexo do pequeno número de indivíduos em flor e do reduzido número de flores por indivíduo, o que evidenciou evento fenológico assincrônico (C. S. P Silva, dados não publicados). Deste modo, como análise comparativa em área queimada (Goiânia, GO) e não queimada (Silvânia, GO), nota-se que o fogo estimula o florescimento sincrônico entre os indivíduos de $S$. odoratissima, comportamento que está em concordância com outras espécies pirofíticas do estrato herbáceo e subarbustivo das savanas tropicais (Coutinho, 1977; Miranda e Klink, 1996; Munhoz e Felfili, 2005).

Conforme a definição de Coutinho (2002), espécie pirofítica é aquela que se encontra bem adaptada a uma condição ambiental que inclui a presença de queimadas, sendo capaz de restaurar rapidamente a parte aérea e iniciar a sua reprodução sexuada, estratégia ecológica comumente observada em outras espécies subarbustivas de cerrado (Coutinho, 1977). Por outro lado, é válido ressaltar que a maioria das espécies consideradas pirofíticas carece de investigações de longo prazo, pois não se sabe se as mesmas apresentam um intervalo maior entre os eventos reprodutivos após o fogo.

\section{Morfologia e visitantes florais}

Analisando os aspectos morfológicos das espécies de Rutaceae já estudadas, verifica-se uma grande variedade nas formas de estruturas florais, o que evidencia a existência de diferentes síndromes de polinização para a família, como a miiofilia, ou polinização por moscas, em Esenbeckia leiocarpa Engl. (Crestana et al., 1983); a falenofilia, ou polinização por mariposas de hábito crepuscular ou noturno, em Galipea jasminiflora (A. St.-Hil.) Engl. (Piedade e Ranga, 1993) e a ornitofilia, ou polinização por pássaros, em Hortia brasiliensis Vand. ex DC. (Barbosa, 1999).
As flores de $S$. odoratissima possuem atributos da morfologia floral que as enquadram na síndrome de falenofilia proposta por Faegri e van der Pijl (1979), tais como antese crepuscular, odor adocicado, coloração branca das pétalas e ausência de guias nectaríferos na corola. A concentração de açúcares no néctar (16,4\%) é também equivalente à amplitude de outras espécies falenófilas já estudadas por Oliveira (1996). Além disso, inflorescências situadas na parte superior da copa expõem as flores facilitando o acesso aos polinizadores. Tão importante quanto a morfologia floral para a atração de agentes polinizadores de hábito crepuscular ou noturno, são o arranjo terminal das inflorescências e o odor agradável e adocicado exalado pelas flores, os quais assumem o papel de unidade de atração olfativa, que é comum na síndrome da falenofilia. No entanto, essas características não limitam a visitação de insetos oportunistas, tais como moscas, vespas, besouros, formigas e abelhas que procuram as flores para a pilhagem de pólen e néctar, o que pode indisponibilizar o emprego destes recursos na polinização cruzada.

A curta longevidade floral deixa as flores de S. odoratissima expostas aos polinizadores por um período reduzido, o que pode explicar, em parte, a baixa produção natural de frutos. Isso quer dizer que a curta longevidade floral e a floração concentrada em um curto intervalo de tempo impedem que os polinizadores efetivos (mariposas) realizem uma maior quantidade de visitas em dias distintos, o que pode elevar os níveis de polinização para a espécie e, conseqüentemente, uma maior formação de frutos. Porém, é válido ressaltar que o caráter fragmentado e o grau de perturbação da área de estudo podem afugentar as mariposas, interferindo, também, na formação de frutos.

\section{Sistema de reprodução}

A xenogamia é o sistema de reprodução predominante entre as espécies de Rutaceae, sendo observada em Galipea jasminiflora (Piedade e Ranga, 1993), Hortia brasiliensis (Barbosa, 1999) e Esenbeckia leiocarpa (Crestana et al., 1983). A floração sincrônica após a influência do fogo parece favorecer a xenogamia, pois cria condições favoráveis para a transferência de pólen devido a maior disponibilidade de flores. Porém, o au- 
mento de recursos também atrai uma grande quantidade de visitantes florais oportunistas interessados apenas na coleta de pólen ou néctar.

O cálculo do índice de incompatibilidade (ISI) sugere que $S$. odoratissima é autocompatível (ISI $=0,55$ ), pois conforme o proposto por Bullock (1985), valores superiores a 0,20 indicam sistema reprodutivo autocompatível e valores inferiores a 0,20 indicam sistema auto-incompatível. Resultados similares também foram registrados por Barbosa (1999) em Hortia brasiliensis (ISI $=0,50)$ e por Piedade e Ranga (1993) em Galipea jasminiflora $(\mathrm{ISI}=0,82)$.

O índice de eficácia reprodutiva, que estima a máxima condição de polinização e é, simultaneamente, uma medida da eficiência dos visitantes como polinizadores está entre 0,16 e 0,36 em áreas florestais. Em ambientes de cerrado, o índice varia em torno de 0,50 (Borges, 2000). O índice de 0,39 encontrado em $S$. odoratissima pode evidenciar uma provável dificuldade na transferência de grãos de pólen, sugerindo uma possível deficiência dos visitantes florais como polinizadores. No entanto, a alta abundância de $T$. spinipes que eventualmente encosta o corpo impregnado de pólen no estigma da flor, pode ter participação importante na produção de frutos, atuando como polinizador secundário e contribuindo no índice de eficácia reprodutiva. Como a oferta de flores abertas se manteve relativamente alta durante o período de floração, estas abelhas apresentaram uma baixa movimentação entre os indivíduos e tinham uma longa permanência na mesma planta, o que pode ter contribuído no índice de eficácia reprodutiva, pois a espécie é autocompatível.

Os resultados advindos desta pesquisa contribuíram para a ampliação dos conhecimentos a respeito das estratégias ecológicas de $S$. odoratissima (manacá). No entanto, a sua biologia reprodutiva e seu sistema de polinização ainda precisam ser mais bem estudados, visto que se trata de uma espécie pouco investigada cientificamente, apesar do amplo reconhecimento na medicina popular e da ameaça de extinção.

\section{Agradecimentos}

À Carolina Soares (UFG-GO) pela confecção da prancha ilustrativa e ao Pedro Assumpção da Costa e Silva (UnB-DF) pela sua finalização. Ao Dr. Paulo Eugênio de Oliveira e M.Sc. Felipe W. Amorin da Universidade Federal de Uberlândia (UFU-MG), pela cessão do laboratório e valiosa colaboração nos experimentos de crescimento de tubo polínico. Ao Dr. Nilton Bellizi (UEG-GO) pela identificação dos insetos. Aos familiares e amigos que se dispuseram em auxiliar nos trabalhos de campo.

\section{Referências}

Almeida, S.; Proença, C. E. B.; Sano, S. M.; Ribeiro, J. F. 1998. Cerrado: espécies vegetais úteis. EMBRAPA, Planaltina, Brasil, 464pp.

Barbosa, A. A. A. 1999. Hortia brasiliana Vand. (Rutaceae): polinização por aves Passeriformes no cerrado do sudeste brasileiro. Revista Brasileira de Botânica, 22: 99-105.

Batalha, M. A.; Aragaki, S.; Mantovani, W. 1997. Variações fenológicas das espécies do Cerrado em Emas (Pirassununga, SP). Acta Botanica Brasílica, 11: 61-78.

Batalha, M. A.; Mantovani, W. 2000. Reproductive phenological patterns of cerrado plant species at the Pé-de-Gigante Reserve (Santa Rita do Passa Quatro, SP, Brazil): a comparasion between herbaceous and wood floras. Revista Brasileira de Biologia, 60 (1): 129-145.

Bawa, K. S. 1974. Breeding systems of tree species of a lowland tropical community. Evolution, 28: 85-92.

Borges, H. B. N. 2000. Biologia reprodutiva e conservação do estrato lenhoso numa comunidade do Cerrado. Tese de Doutorado, UNICAMP, Brasil, 114pp.

Brasil. 1992. Normais Climáticas (1961-1990). Ministério da Agricultura e Reforma Agrária. Secretaria Nacional de Irrigação, Departamento Nacional de Meteorologia, Brasília, Brasil, 84pp.

Bulhão, C. F.; Figueiredo, P. S. 2002. Fenologia de leguminosas arbóreas em uma área de cerrado marginal no nordeste do Maranhão. Revista Brasileira de Botânica, 25: 361-369.

Bullock, S. H. 1985. Breending system in the flora of a tropical deciduous forest in Mexico. Biotropica, 17 (4): 287-301.

Coutinho, L. M. 1977. Aspectos ecológicos do fogo no cerrado. II. As queimadas e a dispersão de sementes em algumas espécies anemocóricas do estrato herbáceo-subarbustivo. Boletim de Botânica, 5: 57-64.

Coutinho, L. M. 1978. Aspectos ecológicos do fogo no cerrado. I. A temperatura do solo durante as queimadas. Revista Brasileira de Botânica, 1: 93-96.

Coutinho, L. M. 2002. O bioma Cerrado. In: Klein, A. L. (Org.). Eugen Warming e o cerrado brasileiro: um século depois. Ed. UNESP, Imprensa Oficial do Estado, São Paulo, Brasil, p.77-91. 
Crestana, C. S. M.; Dias, I. S.; Kageyama, P. Y. 1983. Biologia floral do guarantã, Esenbeckia leiocarpa Engl. (Rutaceae). Silvicultura, 28: 35-38.

Dafni, A. 1992. Pollination ecology: a practical approach. Oxford University Press, New York, USA, 250pp.

Eiten, G. 1994. Vegetação do Cerrado. In: Pinto, M. N. (coord.). Cerrado: caracterização, ocupação e perspectivas. $2^{\text {a }}$ ed. Universidade de Brasília/ SEMATEC, Brasília, Brasil, p.9-65.

Faegri, K.; van der Pijl., L. 1979. The principles of pollination ecology. Pergamon Press, Oxford, UK, 239pp.

Fournier, L. A. 1974. Un método cuantitativo para la medición de características fenológicas en árboles. Turrialba, 24: 422-423.

Freitas, C. M. J.; Guedes, M. L. S; Velozo, E. S. 2002. Extração com solvente e fluido supercrítico dos constituintes do caule subterrâneo de Spiranthera odoratissima A. St.-Hil. (Rutaceae). Revista Brasileira de Farmacognosia, 12 (supl.): 19-21

Lenza, E.; Klink, C. A. 2006. Comportamento fenológico de espécies lenhosas em um cerrado sentido restrito de Brasília, DF. Acta Botanica Brasílica, 29 (4): 627-638.

Martin, F. W. 1959. Staining and observing pollen tubes by means of fluorescence. Stain Technology, 34: 125-128.

Matos, L. G.; Pontes, I. S.; Tresvenzol, L. M. F.; Paula, J. R.; Costa, E. A. 2004. Analgesic and anti-inflammatory activity of the ethanolic extract from Spiranthera odoratissima A. St.-Hil. roots. Phytotherapy Research, 18 (12): 963-966.

Mendonça, M. P.; Lins, L. V. (orgs). 2000. Lista vermelha das espécies ameaçadas de extinção da flora de Minas Gerais. Fundação Biodiversitas, Fundação Zoo-Botânica de Belo Horizonte, Brasil, 160pp.

Miranda, H. S.; Klink, C. A. 1996. Proteção contra o fogo e seu efeito na distribuição e composição de espécies de cinco fisionomias de cerrado. In: Miranda, H. S.; Saito, C. H. \& Dias, B. F. S (orgs). Impactos de queimadas em áreas de cerrado e restinga. Universidade de Brasília, Brasília, Brasil, p.37-45.

Munhoz, C. B. R.; Felfili, J. M. 2005. Fenologia do estrato herbáceo-subarbustivo de uma comunidade de campo sujo na Fazenda Água Limpa no Distrito Federal, Brasil. Acta Botanica Brasílica, 19 (4): 979-988.
Myers, N.; Mittermeier, R. A.; Mittermeier, C. G.; Fonseca, G. A. B.; Kent, J. 2000. Biodiversity hotspots for conservation priorities. Nature, 403: 853-858.

Oliveira, P. E. 1996. Dioecy in the Cerrado vegetation of Central Brazil. Flora, 191: 235-243.

Oliveira, P. E.; Gibbs, P. E. 2000. Reproductive biology of woody plants in a cerrado community of the central Brazil. Flora, 195: 311-329.

Oliveira, R. S.; Bezerra, L.; Davidson, E. A.; Pinto, F.; Klink, C. A.; Nepstad, D. C.; Moreira, A. 2005. Depp root function in soil water dynamics in cerrado savannas of central Brazil. Functional Ecology, 19: 574-581.

Piedade, L. H.; Ranga, N. T. 1993. Ecologia da polinização de $G a-$ lipea jasminiflora Engler (Rutaceae). Revista Brasileira de Botânica, 16: 151-157.

Raison, R. J. 1979. Modification of the soil environment by vegetation fires, with particular reference to nitrogen transformations. Plant and soil, 51: 73-108.

Sarmiento, G.; Monasterio, M. 1983. Life forms and phenology. In: Bourlière, F. (Org.). Ecosystems of the world: tropical savannas. Elsevier, Amsterdan, Holanda, p.79-108.

Silva, C. S. P. 2004. Fenologia e biologia reprodutiva de Spiranthera odoratissima A. St.-Hil. (Rutaceae). Monografia de Graduação, Universidade Estadual de Goiás, Anápolis, Brasil, 42pp.

Spina, A. P.; Ferreira,W. M.; Leitão Filho, H. F. 2001. Floração, frutificação e síndromes de dispersão de uma comunidade de Floresta de Brejo na região de Campinas (SP). Acta Botanica Brasílica, 15 (3): 132-138.

Tresvenzol, L. M.; Paula, J. R.; Ricardo, A. F.; Ferreira, H. D.; Zatta, D. T. 2006. Estudo sobre o comércio informal de plantas medicinais em Goiânia e cidades vizinhas. Revista Eletrônica de Farmácia, 3 (1): 23-28.

Vieira, R. F.; Martins, M. V. M. 2000. Recursos genéticos de plantas medicinais do Cerrado: uma compilação de dados. Revista Brasileira de Plantas Medicinais, 3 (1): 13-35.

Zapata, T. R.; Arroyo, M. T. K. 1978. Plant reproductive ecology of a secondary deciduous tropical forest in Venezuela. Biotropica, 10 (3): 221-230. 